\title{
Computed tomography and childhood seizure disorder in Ibadan
}

\author{
*M. O. Obajimi', O.J. Fatunde', A. O. Ogunseyinde', O. O. Omigbodun', \\ O. M. Atalabi', and R. U.Joel' \\ Departments of Radiology', Paediatrics ${ }^{2}$ and Psychiatry ${ }^{3}$ \\ University College Hospital, Ibadan, Nigeria.
}

\begin{abstract}
Summary
Background: Computed Tomography (CT) is an important tool for neuroimaging, it offers an opportunity to investigate structural lesions as a cause of seizures with little morbidity. This study is designed to evaluate it's applicability in children with epileptic seizures. Method: It is a descriptive study of the CT scans of the 103 consecutive children who were referred to the $\mathrm{CT}$ suite of the University College Hospital on account of seizure disorders over a 5 year period (1997 - 2001).

Results: Only $103(4.6 \%)$ of the subjects who had cranial scans done in five years were children with seizures disorders. The CT scans were abnormal in $53(51.5 \%)$. Hydrocephalus was the most common finding in 14 $(13.6 \%)$. Cerebral atrophy and infarct were reported in $10.6 \%$ and $8.7 \%$ respectively. The outlined cranial fractures found in $6.8 \%$ were all depressed. $A$ high incidence $(74.4 \%)$ of abnormal scans was reported in the children with partial seizures. Thirty-three $(62.3 \%)$ of the abnormal scans were amenable to surgery. The presence of neurologic deficit increased the yield of abnormal CT features.

Conclusion: CT scans are of extreme value in the screening and definitive evaluation of seizures in children. It is advocated for excluding treatable conditions and monitoring progression of the disorder.
\end{abstract}

Keywords: Seizure disorder, Computed Tomography, Childhood.

\section{Résumé}

Introduction: Tomographie informatique, computed tomography $(\mathrm{CT})$ est un instrument très important pour neuroimagerie; il donne l'occasion d'examiner les lesions structurales comme la cause des crise avec un peu de la morbidité. L'objet de cette étude est d'évaluer son applicabilité pour des enfants atteints de la crise épileptique.

Méthode: Il s'agit d'une étude descriptive d'examen au scanneur chez 103 enfants consécutifs qui ont été envoyés à la suite $\mathrm{CT}$, du collège hospitalier universitaire en raison de trouble de la crise au cours d'une période de 5 ans (1997-2001).

Resultats: Seulement 103 soit $4,6 \%$ des sujets chez lesquels on a fait le scanneur cranien dans cinq ans étaient des enfants atteints des troubles des crises. Le CT scanneur était anormal chez 53 soit 51,5\%. L'hydrocéphalée était le résultat le plus courant dans 14 soit $13,6 \%$. L'atrophie cérébrale et infarctus ont été rapportés recenses en 10,6\% et $8,7 \%$ respectivement. Le outline de la fracture craniéne trouvé en $6,8 \%$ ont été tous en depression. Une incidence élevée $74,4 \%$ des scanneur anormal était rapporté chez des enfants atteints des crises partielles. Trente trios $(62,3 \%)$ de scanneur anormal étaient traité à travers l'intervention chirurgicale. La présence du déficit neurologique a augmenté le résultat des traits de CT anormal.

Conclusion: Le CT Scanneur est d'une valeur extrême dans le test des dépistage et dans l'évaluation définitive des crises chez des enfants. On préconise son utilisation à l'éxception des conditions guérisable et le contrôle du développment de ce trouble.

\section{Introduction}

In the last two decades, neuroradiologic imaging modalities like the Computed Tomography (CT) and the Magnetic Resonance Imaging (MRI) have facilitated remarkable advances in the evaluation of neurological and psychiatric disorders. MRI is superior to $\mathrm{CT}$ in that it is more sensitive, produces better resolution especially of the posterior fossa and allows for multiplanar imaging . Despite these advantages of MRI, CT can be obtained in a few seconds and therefore significantly less sensitive to patient motion which could degrade image quality. ${ }^{2}$ As a result of this relatively longer scan time Magnetic Resonance Imaging in children will require sedation and monitoring. In addition children who are claustrophobic will find it difficult to tolerate the enclosed space of the MRI scanner. These factors make Computed Tomography an important imaging tool for children and it is more than sufficient for detecting structural abnormalities ${ }^{3 .}$

$\mathrm{CT}$ also offers an opportunity to investigate structural lesions as a cause of seizures with little morbidity. This procedure has been described in adults in Ibadan ${ }^{4}$ and we believe it is equally applicable in children.

Epileptic seizures are sudden, involuntary behavioural events associated with either excessive or hyper-synchronous electrical discharges in the brain. The aetiology of these seizures in children is rarely documented 5 , however statistically common causes of this neuronal hyper- excitability, generally involve either structural abnormalities of the brain or biochemical aberrations of a metabolic, infectious, or other physical aetiology. ${ }^{6}$ Among the most common aetiologies are congenital malforma- 
tions. structural malformations, intrauterine infections including the 'TORCHES' and HIV', all of which may be diagnosed using neuroradiologic imaging techniques.

In developing countries like Nigeria CT and MRI are fairly new imaging techniques ${ }^{7}$. In Nigeria MRI is virtually inaccessible as it is currently available in only one centre. Although CT is now widely available in the country its cost is prohibitive and beyond the reach of the common man, as a CT scan study costs about 150 , U.S dollars ${ }^{8.9}$. This important investigation may therefore not be requested as often as it should be even though identifying specific aetiology for seizure disorder has very important implications for management as well as prognostication 5

This study is designed to evaluate the usefulness of CT in defining the aetiology of seizures in children by documenting their diverse CT findings.

\section{Subjects and Method}

CT was performed on 103 children aged one month to 16 years referred to the CT suite of the Radiology Department in the University College Hospital Ibadan with a history of seizures. The study was carried out over a five-year period, from January 1997 to December 2001. Most of the children ( $85.4 \%$ ) were referred from the paediatrics department of the University College Hospital while the others were referred from other hospitals within the country. The patients' records were reviewed to assess the following; age, sex, seizure type, neurologic examination and relevant antecedent history.

CT scans were done using the GEC 9000 (whole body) scanner. The CT protocols include axial slices of the brain obtained at $4 \mathrm{~mm}$ cuts from the base of the skull to the posterior fossa and $10 \mathrm{~mm}$ cuts to the skull vertex. Pre and post contrast slices were obtained except in the cases with an antecedent history of trauma due to reasons previously stated by the same author ${ }^{8}$. The radiological CT patterns were then assessed.

For the purpose of this study, the seizures were classified into four groups (Table 5) using the revised International Classification of seizures based on a more contemporary understanding of seizure pathophysiology. ${ }^{10}$. Focal atrophy was defined as a focal area of low density in the cerebral parenchyma in association with dilatation and shift of the adjacent ventricle towards the side of atrophy. General atrophy was recorded when both the lateral ventricle and cortical sulci were dilated.

\section{Results}

Of the 2,265 cranial CT scans done in the department of radiology over this five- year period only 103 (4.6\%) were done for children with seizures. The patient population comprised of 71 males and 32 females giving a 2.2: 1 ratio. This pattern of male predominance was observed in all the age groups.

The ages of the patients ranged from 1 month to 10 years. The mean age was 7.4 years $(S D \pm 4.6)$. The peak incidence occurred in the five to ten-year age group 39
Table 1 Age and sex distribution of children with seizure disorder.

$\begin{array}{lccc}\text { Age Group } & \begin{array}{l}\text { Male } \\ \text { No(\%) }\end{array} & \begin{array}{l}\text { Female } \\ \text { No }(\%)\end{array} & \begin{array}{l}\text { Total } \\ (\%)\end{array} \\ \text { <1 month } & - & - & - \\ \text { I month-12months } & 7(6.8) & 4(3.9) & 11(10.7) \\ \text { 13months-4 years } & 19(18.5) & 5(4.9) & 24(23.4) \\ \text { 5-10 years } & 28(27.2) & 11(10.7) & 39(37.9) \\ \text { 11.15 years } & 15(14.6) & 11(10.7) & 26(25.3) \\ >15 \text { years } & 2(1.9) & 1(0.97) & 3(2.9) \\ \text { Total (\%) } & 71(68.9) & 32(31.1) & 103(100)\end{array}$

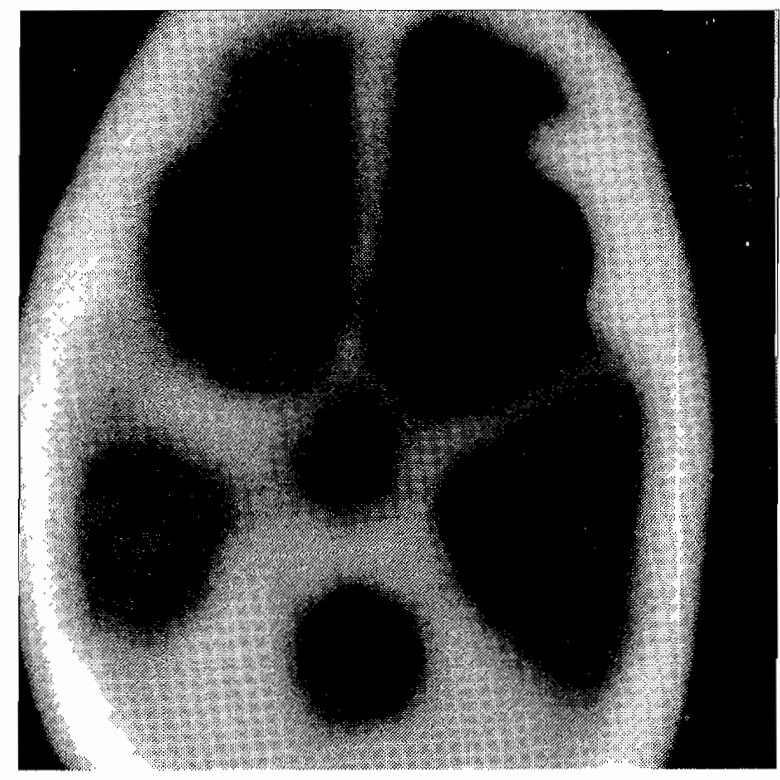

Fig. 1. Hypodence dilated ventricles (communicating Hydrocephalus) with thining of the brain mantle

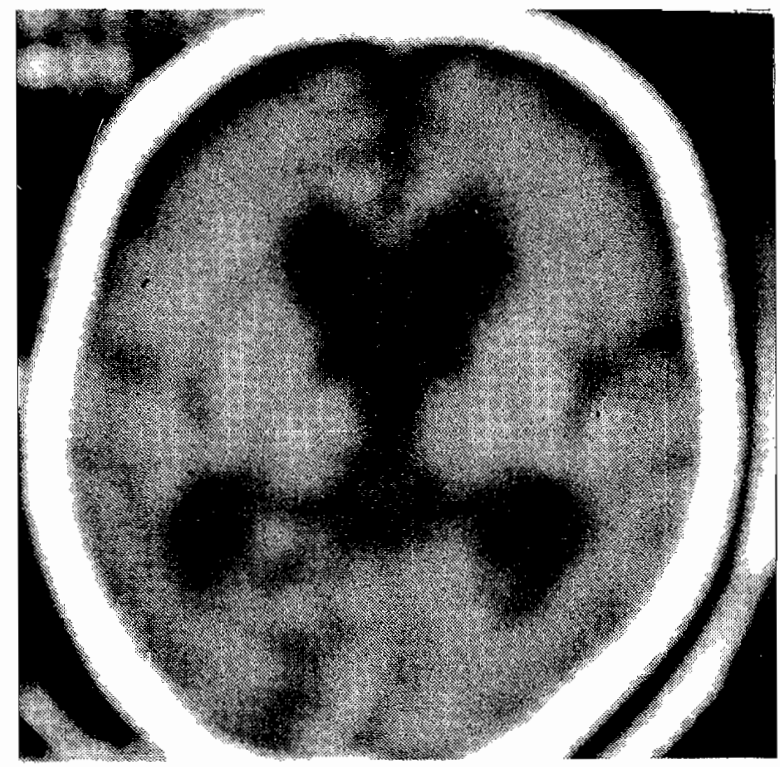

Fig. 2. Irominent sulci, sylvian fissures and ventricles in cerebral atrophy. 
Table 2 Distribution of $\mathrm{CT}$ findings and age group

\section{C'1}

Findings

\section{Age Distribution}

<lmonth 1month- 13months- 5years12 montlis 4years 10years 11-15years >15years Total \%

\begin{tabular}{|c|c|c|c|c|c|c|c|}
\hline Normal & - & 4 & 15 & 15 & 15 & 1 & $50(48.5)$ \\
\hline Hydrocephalus & - & 1 & 3 & 8 & 2 & - & $14(13.6)$ \\
\hline Atrophy & - & 3 & 4 & 1 & 3 & - & $11(10.6)$ \\
\hline $\mathrm{Cl}$ & - & - & - & 5 & 4 & - & $9(8.7)$ \\
\hline Mass lesion & - & - & 1 & 6 & 1 & 1 & $9(8.7)$ \\
\hline Fracture & - & 1 & 1 & 3 & 2 & - & $7(6.8)$ \\
\hline $\mathrm{EH}$ & - & 2 & 1 & 2 & - & - & $5(4.9)$ \\
\hline $\mathrm{CH}$ & - & - & 1 & 2 & 2 & - & $5(4.9)$ \\
\hline $\mathrm{CO}$ & - & - & - & 3 & - & - & $3(2.9)$ \\
\hline Brain Anomaly & - & - & 1 & 1 & - & - & $2(1.9)$ \\
\hline Total (\%) & - & $11(10.7 \%)$ & $27(26.2 \%)$ & $46(44.7 \%)$ & $29(28.2 \%)$ & $2(1.9 \%)$ & 115 \\
\hline \%Abnormal & - & 63.6 & 44.4 & 67.3 & 48.3 & 50 & \\
\hline
\end{tabular}

$E H=$ Extraparenchymal Haemorthage

$\mathrm{Cl}=$ Cerebral hifarct

$\mathrm{CH}=$ Cerebral Haemonhage

$(37.9 \%)$ and only $2(2.9 \%)$ were above 15 years. (see table 1).

Table 2 presents the relationship of $\mathrm{CT}$ scan result and the age of the children at the time of the study. Notably no child was scanned in the first month of life. Forty six $(44.7 \%)$ were scanned in the $5-10$ year age group. This was the peak incidence in the children studied and it was followed by the $11-15$ year-age group (28.2\%) and the 13 months -4 year age group $27(26.2 \%)$. A high incidence $(63.6 \%)$ of abnormal scans were noted in the $5-10$ years while the children in the first year of life recorded

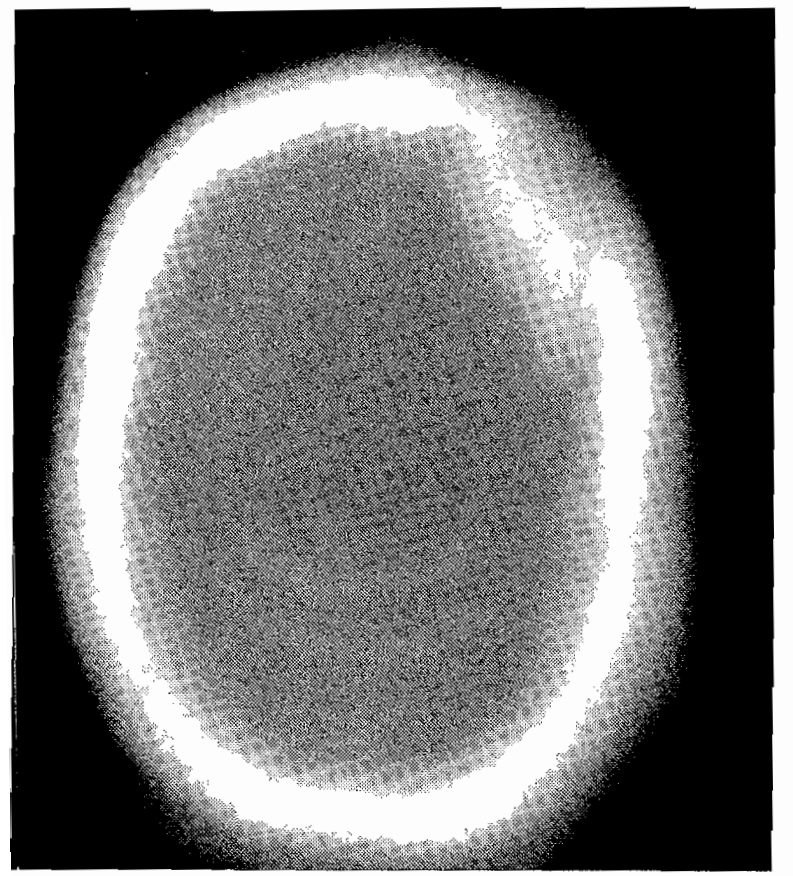

Fig. 3. Bony window of axial CT scan showing depressed left frontal skull fracture

$$
\begin{aligned}
& C O=\text { Oedema } \\
& S O L=\text { Space Occupying Lesion } \\
& C B A=\text { Congenital Brain Abnormality }
\end{aligned}
$$

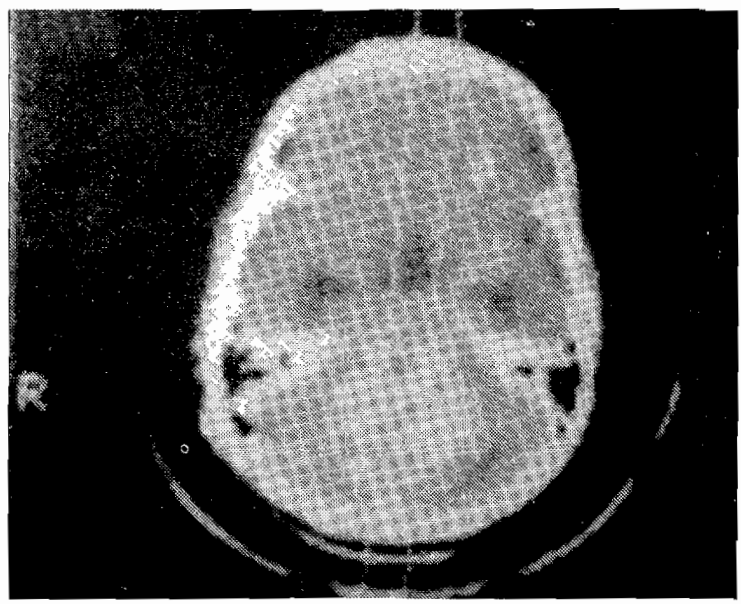

Fig. 4. Midline hyperdense posterior fossa Astrocytoma

\section{$63.3 \%$}

The spectrum of CT findings are listed in table 3. These findings are tabulated with the relevant antecedent history. The CT findings were normal in 50(48.5\%) while the most cornmon abnormal CT finding was hydrocephalus in $14(13.6 \%), 8$ of which were the communicating variety (Fig. 1). Eleven children showed CT evidence of cerebral atrophy. Cerebral infarct and space occupying mass lesion were present in $9(8.7 \%)$ each. All the five cerebral haemorrhages were acute and therefore appeared hyperdense. There were five cases of extraparenchymal haemorrhage made of 4 chronic subdural and one acute extradural bleeds. The two children with congenital brain anomaly showed dilatation of all the ventricles which were connected to the basal cistern posteriorly by a narrow channel consistent with a Dandy Walker Syndrome.

Fifty-three $(45.3 \%)$ scans were done for just a history of seizures of which $24(45.3 \%)$ were abnormal; this 
Table 3 CT findings and clinical history

\begin{tabular}{|c|c|c|c|c|c|c|c|c|c|}
\hline $\begin{array}{l}\text { C'T } \\
\text { findings }\end{array}$ & $\begin{array}{l}\text { Seizures } \\
\text { only }\end{array}$ & $\begin{array}{l}\text { Post } \\
\text { traumatic }\end{array}$ & Headaches & $\begin{array}{l}\text { CNS } \\
\text { Infection }\end{array}$ & NN.J & lever & $\begin{array}{l}\text { Birth } \\
\text { Asphyxia }\end{array}$ & $\begin{array}{l}\text { Brain } \\
\text { malformation }\end{array}$ & Total \\
\hline Normal & 29 & 10 & 3 & - & 1 & 5 & 2 & - & 50 \\
\hline Hydrocephalus & 5 & 1 & 1 & 6 & - & - & - & 1 & 14 \\
\hline Atrophy & 4 & 1 & - & 3 & - & 1 & 2 & - & 11 \\
\hline $\mathrm{Cl}$ & 7 & 1 & - & - & - & 1 & - & - & 9 \\
\hline SOL & 5 & - & 4 & - & - & - & - & - & 9 \\
\hline Fracture & - & 7 & - & - & - & - & - & - & 7 \\
\hline EH & 1 & 3 & - & - & . & 1 & - & - & 5 \\
\hline $\mathrm{CH}$ & - & 5 & - & - & - & - & - & - & 5 \\
\hline $\mathrm{CO}$ & 2 & - & 1 & - & - & - & - & - & 3 \\
\hline CBA & - & - & 2 & - & - & - & - & - & 2 \\
\hline Total & 53 & 28 & 11 & 9 & 1 & 7 & 5 & 1 & 115 \\
\hline$\%$ Abnormal & 45.3 & 64.3 & 72.7 & 100 & 0.00 & 28.6 & 50 & 100 & \\
\hline
\end{tabular}

NNJ = Neonatal Jandice

CNS $=$ Central Nerrous System

EH = Extraparenchymal Hacmorrhage

CI $=$ Cerebral linfaret

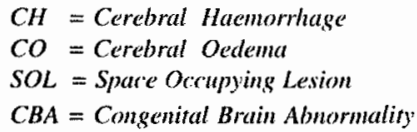

$\mathrm{CH}=$ Cerebral Hacmorrhage

$C O=$ Cerebral Oedema

$S O L=$ Space Occupying Lesion

$C B A=$ Congenital Brain Abnormality

was followed by 28 done for a history of seizures subsequent to trauma. Eighteen $(64.3 \%)$ of this category showed abnormal CT findings. All the 9 children scanned for seizures consequent to CNS infection were abnormal. The mass lesions comprised of 2 craniopharyngiomas, 2 posterior fossae astrocytomas (Fig.4), one metastatic deposit and one lymphoma.

Table 4 is a correlation of CT findings and neurologic deficit. Neurologic deficit was present in $32(31.1 \%)$ of the children. This deficit was common in children with cerebral infarct and those with space occupying mass lesion, while no deficit was reported in children with cerebral haemorrhage.

Table 5 is a table of seizure patterns in children compared with the CT findings. The patients were divided into 4 groups as stated in the methodology. The highest incidence of abnormal scans (100\%) was recorded in the children with partial seizures and secondary generalisation. Out of the 84 children with generalised tonic clonic seizures $42(50 \%)$ were abnormal. The other percentage incidences are reported in this table.

\section{Discussion}

The low scan frequency $4.6 \%$, reported in this study might have been due to several reasons.

Firstly the prohibitive cost may discourage doctors from referring unless it is absolutely necessary and parents may refrain from bringing their children even after referral. In addition the electro encephalogram EEG may assist in determining the nature of seizures and there may be no indication for further neuro-imaging ${ }^{6}$.

The highest incidence of seizures in our study occurred

Table 4 Correlation of CT findings and Neurologic deficit

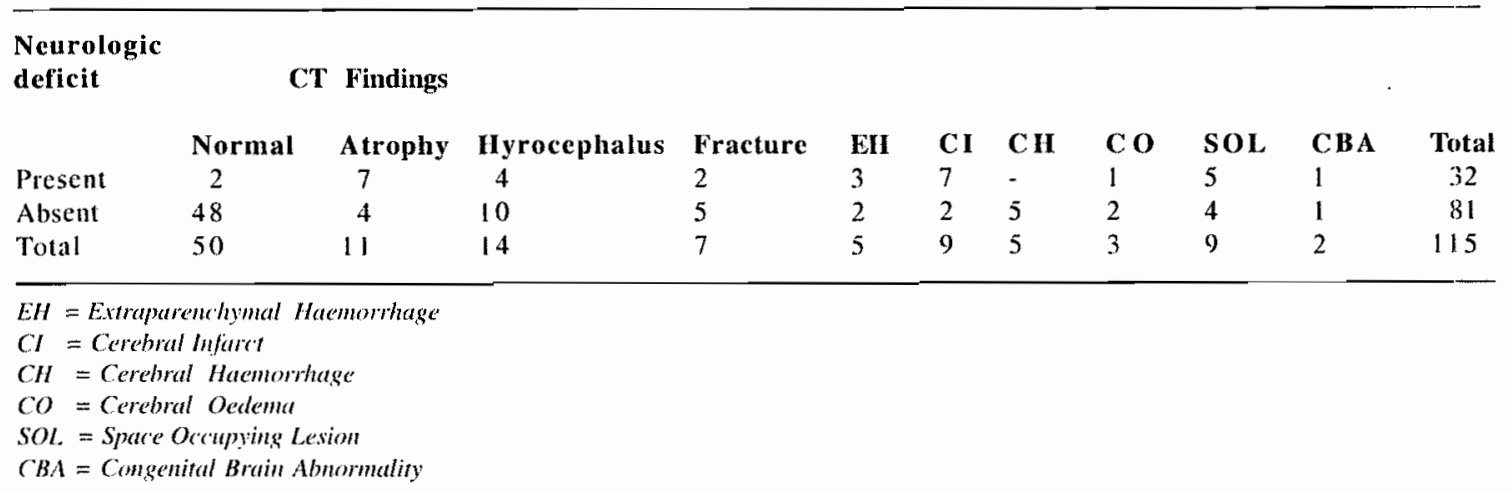


Talsle 5 CT findings and seizure patterns

\begin{tabular}{|c|c|c|c|c|c|}
\hline CT Findings & $\begin{array}{l}\text { Simple } \\
\text { Partial }\end{array}$ & $\begin{array}{l}\text { Complex } \\
\text { Partial }\end{array}$ & $\begin{array}{l}\text { Partial } \\
\text { Secondarily } \\
\text { Generalised }\end{array}$ & $\begin{array}{l}\text { Generalised } \\
\text { Tonic } \\
\text { Clonic }\end{array}$ & Total (\%) \\
\hline Normal & 4 & 4 & - & 42 & $50(48.5)$ \\
\hline Hydrocephalus & 4 & 4 & - & 6 & $14(13.6)$ \\
\hline Atrophy & 1 & - & 1 & 9 & $1 \mathrm{I}(10.6)$ \\
\hline $\mathrm{Cl}$ & 2 & 2 & 1 & 4 & $9(8.7)$ \\
\hline SOL & 1 & - & I & 7 & $9(8.7)$ \\
\hline Cranial Fracture & 1 & 1 & 1 & 4 & $7(6.8)$ \\
\hline $\mathrm{EH}$ & 2 & - & - & 3 & $5(4.9)$ \\
\hline $\mathrm{CH}$ & - & 1 & - & 4 & $5(4.9)$ \\
\hline $\mathrm{CO}$ & - & - & - & 3 & $3(2.9)$ \\
\hline CBA & - & - & - & 2 & $2(1.9)$ \\
\hline Total (\%) & $15(14.5 \%)$ & $12(11.7 \%)$ & $4(3.9 \%)$ & $84(81.6 \%)$ & 115 \\
\hline$\%$ Abnormal & 73.3 & 66.6 & 100 & 50 & \\
\hline
\end{tabular}

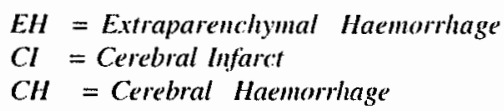

in children of school age, 5-10 years. This is in keeping with studies, which reveal that prevalence of epilepsy is highest among school children. The prevalence of epilepsy in pre school children is 1.5 per 1000 and increases to 5 per 1000 in school age children.". Boys are more likely than girls to have epilepsy, this agrees with our 2.2:1, male female ratio.

Our findings show that $51.5 \%$ of scans were abnormal, this incidence is much higher than the range $30 \%{ }^{5,12}$ - $33 \%{ }^{13}$. described by other authors. It is observed that CT scans done only on account of seizures alone were quite productive as $45.3 \%$ were abnormal. However, scans done for seizures with antecedent history of infection trauma and headaches were of greater yield. The most common abnormality in our study was dilated ventricles or hydrocephalus (13.6\%) Fig. 1, unlike the report by Bachman 5 where atrophy was the most frequent abnormality. In our study 11 children had atrophy, 4 were focal and 7 diffuse (Fig. 2). The latter were found to be frequent in children with birth related insults. Cranial fractures were also demonstrated clearly in $6.8 \%$. Computed Tomography showed that they were all depressed ( Fig.3), accounting for cerebral irritation and subsequent seizures in these children. All the five cases with cerebral haemorrhage were post traumatic confirming the findings by other authors in this age group ${ }^{14.15}$. There was however no report of spontaneous intracranial haemorrhage as reported by Ogunniyi in adults and adolescents ${ }^{4}$

The authors observed significant differences in the incidence of CT abnormality, depending on seizure type. In children with partial seizures or signs of partial onset the scans were abnormal in $74.4 \%$ when compared with $50 \%$ abnormalities recorded in children with generalised tonic seizures Table 5 . This suggests a higher indication
$C O=$ Cerebral Oedema

SOL = Space Occupying Lesion

$C B A=$ Congenital Brain Abnormality for CT Scan requests in children with partial seizures. Like previous authors ${ }^{5,13,16 .}$ our study demonstrated an increase in CT pathology from childhood to teenage, (Table 2). From the CT findings $33(62.3 \%)$ of the 53 abnormal scans were amenable to surgery. They comprised of 5 fractures, 14 hydrocephalus, 3 extraparenchymal haemorrhage, 9 mass lesions and 2 congenital brain abnormalities. Without the CT examination, these treatable causes of seizures may have been missed.

Even though the presence of neurologic deficit increased the yield of abnormal CT scans, over $40 \%$ of the children without deficit had abnormal scans suggesting that the absence of a neurological deficit should not preclude the study in children.

We conclude that Computed Tomographic scans are of extreme value in screening and definitive evaluation of seizures in children. The study reiterates the high probability of abnormal CT scans in the older children; those with positive neurological deficits and clinical manifestations of partial seizures. It is also observed that the benefits of the scans are of particular importance in children with a sudden change of seizure pattern and neurological examination. A CT scan examination is also valuable in excluding a treatable condition or progressive disease

The authors therefore suggest a more frequent use of this non-invasive, prompt and reliable axial imaging technique to improve the management of children presenting with seizures so as to aid diagnosis and prevent further damage to the developing brain of these frequently neglected and vulnerable children.

\section{References}

1. Brant -Zawadzki M. Badami P, Mills, CM, Norman, D 
Nweton. H. Primary intracranial tumour imaging: a comparison of magnetic resonance and CT Radiology. 1984; 150: $435-440$

2. Tartaglino LM, Bello JA. Neuroradiologic imaging in children. Chapter 10 in Kaufman, D.M., Solomon. G.E., Pleffer, C.R. (eds) Child and adolescent Neurology for Psychiatrists; Williams and Wilkins, Baltimore. 1992.

3. Naidich TP, Zimmerman RA. Primary brain tumours in children. Semin Roentgenol. 1984; 19: 100-114.

4. Ogunniyi A Adeyinka A, Fagbemi. SO, R, Falope, ZF. and Oyawole, S.O. A. Computerised Tomographic findings in Adolescent and Adult Nigerian Epileptics West African Journal of Medicine. 1994; 1: 128-131.

5. Bachman DS, Hodgss FJ, Freeman J M. Computed Tomography in chronic seizure disorders of childhood. Paediatrics 1976 ; 58: 828-32.

6. Rother Kaufman, DM, Solomon GE, Pfeffer, CR. Epilepsy Chapter 8 in Child and Adolescent Neurology for Psychiatrists; Williams and Wilkins (eds) Baltimorc. 1992.

7. Obajimi MO, Ogunseyinde, Remi and Sa'ad, S. T. Computed Tomography, evidence of skull fracture in relation to the presence and site and intracranial contusion and haematoma. The Nigerian Postgraduate Medical Journal. 1999; 6: 1-3.

8. Obajimi, MO, Shokunbi, MT, Malomo, AA Agunloye, AM. Computed Tomography (CT) in Civilian gunshot head injuries in Ibadan. In West African Journal of Medi- cine (in the press).

9. Fafowora. OF, Cookey-gam, AI. and Obajimi. MO. Radiological Evaluation of orbital tumous in Ibadan. Nigeria. African Journal of Medicine and Medical sciences. $1996 ; 25: 361-364$.

10. Commission on Classification and Terminology of the International League Against Epilepsy. Proposial for revised clinical and electroencephalographic classification of the epileptic scizures. Epilepsia 1981; 22:489-501.

11. Hauser WA, Hesdorffer DC. Facts about epilensy, New York: Demos Publications. 1990.

12. Patel PJ. Computed Tomography (CT) Scan findings in children with seizure only. Acta Neurol Scand. 1986; 74 : 156-166.

13. Yang, PJ, Berger, PE.. Cohen, ME and Kuffiner, PK.. Computed Tomography and childhood scizure disorders. Neurology. 1979; 29:1084-1088.

14. Abatanga, F,A., Mock, C. N., A survey of paediatric trauma in Kumasi; A hospital based study. Ghana Med J. 1998; 32: 977-980.

15. Obajimi MO, Jumah, K. B., Brakohiappa, W. O., Iddrisu, W. Computed Tomography of head injury in Ghanaian children. The Nigerian Journal of surgical Research $2002 ; 4: 84-88$.

16. Ambrose J. Computerised transverse axial scanning (Tomography); Part 2, Clinical Application. Br J. Radiol. 1973; 46: 1028-1047. 